\title{
Solar-to-Hydrogen Production at 14.2\% Efficiency with Silicon Photovoltaics and Earth-Abundant Electrocatalysts
}

\author{
Jan-Willem Schüttauf, ${ }^{\mathrm{a},=, \mathrm{z}}$ Miguel A. Modestino, ${ }^{\mathrm{b},=, \mathrm{z}}$ Enrico Chinello, ${ }^{\mathrm{b}}$ David Lambelet, ${ }^{\mathrm{b}}$ \\ Antonio Delfino, ${ }^{c}$ Didier Dominé, ${ }^{\mathrm{a}}$ Antonin Faes, ${ }^{\mathrm{a}}$ Matthieu Despeisse, ${ }^{\mathrm{a}}{ }^{\mathrm{Ju}} \mathrm{du}$ (ien Bailat, ${ }^{\mathrm{a}}$ \\ Demetri Psaltis, ${ }^{\mathrm{b}}$ Christophe Moser, ${ }^{\mathrm{b}}$ and Christophe Ballif ${ }^{\mathrm{a}, \mathrm{b}}$
}

${ }^{a}$ Swiss Center for Electronics and Microtechnology (CSEM), Neuchâtel, Switzerland

${ }^{b}$ School of Engineering, École Polytechnique Fédérale de Lausanne, Lausanne, Switzerland

${ }^{c}$ Michelin Recherche et Technique SA, Conception et Développement Michelin, Givisiez, Switzerland

\begin{abstract}
Affordable, stable and earth-abundant photo-electrochemical materials are indispensable for the large-scale implementation of sunlight-driven hydrogen production. Here we present an intrinsically stable and scalable solar water splitting device that is fully based on earth-abundant materials, with a solar-to-hydrogen conversion efficiency of $14.2 \%$. This unprecedented efficiency is achieved by integrating a module of three interconnected silicon heterojunction solar cells that operates at an appropriate voltage to directly power microstructured $\mathrm{Ni}$ electrocatalysts. Nearly identical performance levels were also achieved using a customized state-of-the-art proton exchange membrane (PEM) electrolyzer. As silicon heterojunction solar cells and PEM electrolysis systems are commercially viable, easily scalable and have long lifetimes, the devices demonstrated in this report can open a fast avenue toward the industrialization and deployment of cost effective solar-fuel production systems.
\end{abstract}

(C) 2016 The Electrochemical Society. [DOI: 10.1149/2.0541610jes] All rights reserved.

Manuscript submitted June 30, 2016; revised manuscript received August 3, 2016. Published August 13, 2016.

The past decade has seen an increase in the urgency to substitute fossil fuels with clean and renewable energy sources. Among all of the renewable sources, solar irradiation is undeniably the most prominent option. The average accessible solar power accounts for over $\sim 120$ $000 \mathrm{TW}$ globally; ${ }^{1}$ several thousand times the current global energy needs. ${ }^{2}$ Photovoltaic cells can capture this vast energy resource and convert it into usable electrical energy at high efficiencies. Their implementation in the past years has seen a large growth driven by favorable environmental policies and a steady decrease in their production cost. Although the penetration of photovoltaics has been significant, some challenges for their integration into the electricity grid have started to become evident. Mainly, the intermittent nature of the solar electricity production prevents their large-scale grid implementation without compensation mechanisms that satisfy the demand during low-irradiation periods. Adding energy storage capacity to the grid could directly alleviate the fluctuations on power production. Electrochemical energy storage in batteries is already an interesting option for large-scale stationary energy storage. Electrochemical production of hydrogen from excess solar electricity is also an attractive option for storing solar energy in the form of a fuel which could be used at a later stage for electricity production back into the grid or transportation. ${ }^{3,4}$ Furthermore, hydrogen can be stored for prolonged periods of time, so that solar resources are harvested during high irradiation periods and used throughout the year. Because of these multiple advantages, solar-to-fuel approaches have attracted a lot of interest in the renewable energy field and project themselves as a critical technology to achieve large-scale utilization of solar-energy sources. ${ }^{5-7}$

Despite the strong research interest on solar-hydrogen materials and technologies, there have only been a limited number of demonstrations of solar water splitting devices. Most of these devices show short lifetimes ( $<1$ day), low efficiencies, or use materials and designs that would prevent their practical and economical implementation. ${ }^{6,8}$ Deployable solar-hydrogen devices would need to function stably for years, produce robustly and continuously nearly pure $\mathrm{H}_{2}$ streams, incorporate economically viable photovoltaic and water-splitting components, and operate at high efficiencies so that the energy produced over their lifetime is much greater than the energy required to fabricate and operate the devices. ${ }^{9,10}$ Currently, the best performing systems implement GaAs-based photovoltaic materials to reach high conversion efficiencies. ${ }^{11}$ Although the solar-to-hydrogen efficiency (SHE) of these devices can reach values as high as $24.4 \%,{ }^{11}$ the implementation of III-V semiconductors compromises their economic viability. ${ }^{12}$

\footnotetext{
$=$ These authors contributed equally to this work.

${ }^{\text {z} E-m a i l: ~ j a n-w i l l e m . s c h u e t t a u f @ c s e m . c h ; ~ m i g u e l . m o d e s t i n o @ e p f l . c h ~}$
}

An alternative to this approach was recently proposed where modules of three Copper Indium Gallium Selenide (CIGS) solar cells are connected in series to reach high performance. ${ }^{13}$ While these CIGS modules can reach $17 \%$ solar-to-electricity efficiencies, when integrated with electrocatalysts the SHE is limited to $11 \%$ due to the low open circuit voltage $\left(\mathrm{V}_{\mathrm{OC}}\right)$ of the module. With a series-connected cell based on Perovskite photovoltaics, appropriate $\mathrm{V}_{\mathrm{OC}}$ values for water splitting can be obtained, which have led to their implementation in high-efficiency solar-hydrogen devices (up to $12.7 \%$ SHE). ${ }^{14}$ These materials are promising due to their performance and simple fabrication process, but their large-scale and long-term implementation is still hindered by serious stability issues. ${ }^{14,15}$ On the other hand, crystalline Silicon (c-Si) solar cells show high solar-to-electricity efficiencies, and have demonstrated stabilities in excess of 25 years. Propelled by their attractive performance, they have continuously dominated the market since their inception, ${ }^{16,17}$ with a current worldwide market share greater than $85 \% .{ }^{17,18}$ Their high production volumes have largely contributed to a price drop of $80 \%$ since 2008 , currently reaching levels below $\$ 1$ per watt peak. ${ }^{18}$ Recently, c-Si modules have been implemented in solar-hydrogen devices, demonstrating SHE of $9.7 \% .^{6,19}$ As the $\mathrm{V}_{\mathrm{OC}}$ of the presented c-Si cells is only $\sim 600 \mathrm{mV}$, four cells need to be connected in series to achieve stable water splitting performance. ${ }^{19}$ This results in lower operating currents and limited SHE efficiencies. Alternatively, c-Si-based heterojunction (SHJ) cells ${ }^{20,21}$ can reach $\mathrm{V}_{\mathrm{OC}}$ values in excess of $700 \mathrm{mV}^{21-23}$ These $\mathrm{V}_{\mathrm{OC}}$ values are the highest ones reported for silicon wafer-based technologies, and are predominantly obtained by an excellent interface passivation with a thin $(\sim 5 \mathrm{~nm})$ film of hydrogenated intrinsic amorphous silicon $(\mathrm{a}-\mathrm{Si}: \mathrm{H})$ between the c-Si wafer and the oppositely doped emitter, forming the p-n junction. ${ }^{20}$ We demonstrate in this study that, thanks to their high Voc, three series-connected SHJ cells can already stably drive the water splitting reaction at unprecedented SHE (Fig. 1).

\section{Experimental}

Cell interconnection and module fabrication.-We used 6-inch fully processed bifacial silicon heterojunction (SHJ) cells fabricated on $160 \mu \mathrm{m}$-thick Czochralski wafers, ${ }^{24}$ which have a front and back metallization pattern with three busbars at the same position on each side. The 6-inch cells are cut into small area $\left(2 \times 2 \mathrm{~cm}^{2}\right)$ cells using an infrared laser with a wavelength of $1064 \mathrm{~nm}$ in such a way that they have one busbar exactly on one of the edges of each side. The cells are subsequently interconnected one to another using a CB450 conductive-adhesive paste from Hitachi Chemical Co. Ltd. in Japan, which enables to contact the edge of the front-side of one 


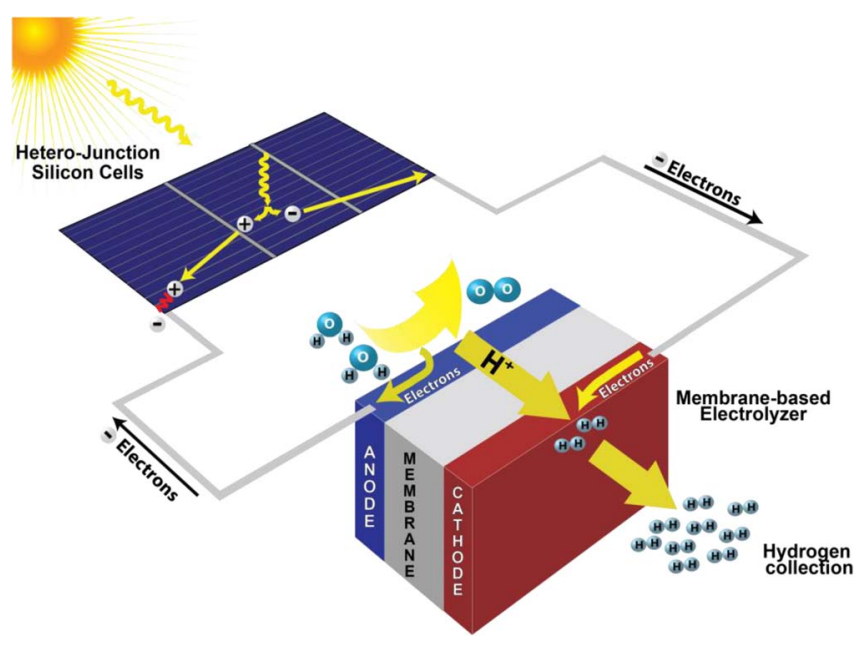

Figure 1. Schematic overview of the solar-driven hydrogen generator. The SHJ module captures sunlight and converts it into electricity directly feeding the electrochemical membrane electrode assembly water-splitting unit. Water is fed in the anodic side, where it is oxidized and oxygen molecules are generated; the simultaneously produced protons migrate across the membrane to the cathode, where they are reduced into molecular hydrogen. The gases can then be collected and stored in their pure form.

cell to the edge of the rear-side of the adjacent cell. This type of advanced cell interconnection, referred to as shingling, enables to optically hide the cell busbar, and to avoid any empty space between the individual cells. This novel interconnection method enables an enhanced current density for the fabricated modules. The three cells integrated in the prototype module are connected in series using this shingling interconnection process. The modules were encapsulated with a $3 S$ R\&D membrane laminator using thermoplastic polyoleofin (TPO) and low-iron solar-grade 3 mm-thick glass on both sides. ${ }^{25}$ The lamination process is performed at $(165 \pm 2)^{\circ} \mathrm{C}$, during $300 \mathrm{~s}$ on pin, followed by $500 \mathrm{~s}$ at $100 \mathrm{mbar}$ and $600 \mathrm{~s}$ at 1000 mbar on a heating plate. A rigid frame is used around the module to avoid breaking the glass during the lamination process. After module fabrication, we applied an anti-reflective foil ${ }^{26,27}$ on top of the module. Such an antireflective foil reduces the reflection losses at the air/glass interface by roughly 5\% (absolute) over the entire relevant wavelength range (300$1100 \mathrm{~nm}$ ), thereby leading to an increase in current density of around $5 \%$. The (average) performance of the individual cells and modules is shown in Figures S1 and S2, and Table S1 of the Supplementary Information.

Cell and module characterization.-The cells were characterized under a Wacom WXS-220S-L2 class A+A+A+ solar simulator under standard test conditions (AM1.5g, $100 \mathrm{~mW} / \mathrm{cm}^{2}, 25^{\circ} \mathrm{C}$ ). The modules were characterized under an in-house developed large-area class AAA solar simulator. ${ }^{28}$ For both cell and module measurements, the solar simulators were calibrated using certified SHJ cells and modules to scale the obtained short circuit current to the certified one.

MEA electrolyzer fabrication, characterization and solar-driven operation.-The SHJ module is electrically coupled with a membrane electrode assembly (MEA) electrolyzer. The MEA used was obtained from Ion Power (HYDrion N117 MEAs) containing Pt and $\mathrm{IrO}_{\mathrm{x}}$ catalyst layer coatings on a $177 \mu \mathrm{m}$ thick Nafion membrane. The electrolyzer flow plates were fabricated using an additive manufacturing tool from Stratasys (Object500 Connex). The flow plates were covered with a thin layer of silver conductive paste from Sigma-Aldrich, and a $500 \mathrm{~nm}$ gold film was evaporated using an EVA760 alliance concept electron beam evaporator. ${ }^{29}$ The MEA was sealed inside a pair of flow plates with a set of titanium (Ti) gas diffusion layers (GDLs) as shown in Figure S3 in the Supplementary Information. Two different
GDLs were implemented to assure uniform electrical resistance and facile water and gas transport. The first coarse Ti GDL was obtained from Sigma-Aldrich (Product number GF03980932 - Ti mesh with $0.23 \mathrm{~mm}$ diameter wire, $60 \times 60$ wire per inch), while the second GDL was based on sintered Ti fibers with fiber diameters of $20 \mu \mathrm{m}$, a density of $600 \mathrm{~g} / \mathrm{m}^{2}$ and porosity of $56 \%$ (Model ST/Ti/20/600/56 from Bekaert Fiber Technologies). The electrochemically active area of the MEA was $1.3 \mathrm{~cm}^{2}$ and the Nafion membrane allowed for the production of two separated streams of $\mathrm{H}_{2}$ and $\mathrm{O}_{2}$ and thus an intrinsically safe operation. The MEA electrolyzer structure is schematically described in Figure S3. All electrochemical measurements were carried out using a Biologic potentiostat VSP-300. A peristaltic pump (New Era Pump Systems Inc. NE-9000) is used to feed the electrolyzer's anodic side with deionized water at a working flow rate 1 $\mathrm{mL} \cdot \mathrm{min}^{-1}$, while the cathodic side was allowed to freely evolve $\mathrm{H}_{2}$. For the collection efficiency measurements, an inverted cylinder water displacement setup was used to characterize the volumes of each gas (Figure S6 in the Supporting Information). For the characterization of the water splitting load presented in Figure 2, the potential applied to the electrolysis units was swept at a scan rate of $20 \mathrm{mV} / \mathrm{s}$. All experiments were carried out at room temperature $\left(20^{\circ} \mathrm{C}\right)$. The module temperature, however, was not specifically controlled and monitored during the prolonged illumination for the stability tests. Due to this prolonged illumination, the module operated at steady-state at a higher temperature.

Alkaline electrolysis with Nickel electrocatalysts.- $\mathrm{Ni}$-foam electrodes were obtained from Markatech International (thickness of 1.6 $\mathrm{mm}$, surface density of $346 \mathrm{~g} / \mathrm{m}^{2}$, porosity $>95 \%$ ). Each Nickel electrode used in the experiments had a projected surface area of $60 \mathrm{~cm}^{2}$. These electrodes were operated under basic electrolytes (1 M KOH) while coupled with the SHJ module. The integrated PV-electrolysis system showed stable and reliable performance for over 100 hours at SHE values ranging between $14.5 \%$ and $14.2 \%$. In order to promote bubble detachment from the foam, the electrolyte was stirred during operation. Within these experiments, the electrodes co-evolved $\mathrm{H}_{2}$ and $\mathrm{O}_{2}$. In order to produce pure gases, anion exchange membranes (AEMs) can be used to separate the oxygen and hydrogen evolution sites. Similar results were attained with the implementations of an AEM between the anode and cathode side (see Figure S4 and S5).

Illumination of SHJ module during water splitting experiments.-The SHJ modules are illuminated with simulated sunlight using a $300 \mathrm{~W}$ solar simulator (Sciencetech SF300) containing an AM 1.5 filter. In order to illuminate uniformly the module area, a lens was used to enlarge the beam width and cover the module area. The simulator power was calibrated to obtain an irradiation of $1000 \mathrm{~W} / \mathrm{m}^{2}$ at the SHJ module surface. Due to illumination beam width limitations and in order to enhance the module performance reducing the peripheral charge recombination losses, the SHJ module was partially shadowed through a mask, which ensured the same illuminated area for the three cells $\left(1.9 \mathrm{~cm}^{2}\right.$ each, $5.7 \mathrm{~cm}^{2}$ total illumination area) and therefore guaranteed an overall high current density.

Light cycling stability tests.-In order to recreate the normal succession of daytime and nighttime, experiments under light and dark conditions were carried out at 30 minutes intervals. Both MEAbased and Nickel bulk water-splitting devices showed consistent operation in every cycle, with unaltered SHE during the illumination intervals. Results are reported in Figure S7 in the Supplementary Information.

The cells and modules were characterized at CSEM in Neuchâtel, Switzerland, and thereafter shipped to EPFL in Lausanne, Switzerland to be integrated and measured with electrolysis units. 

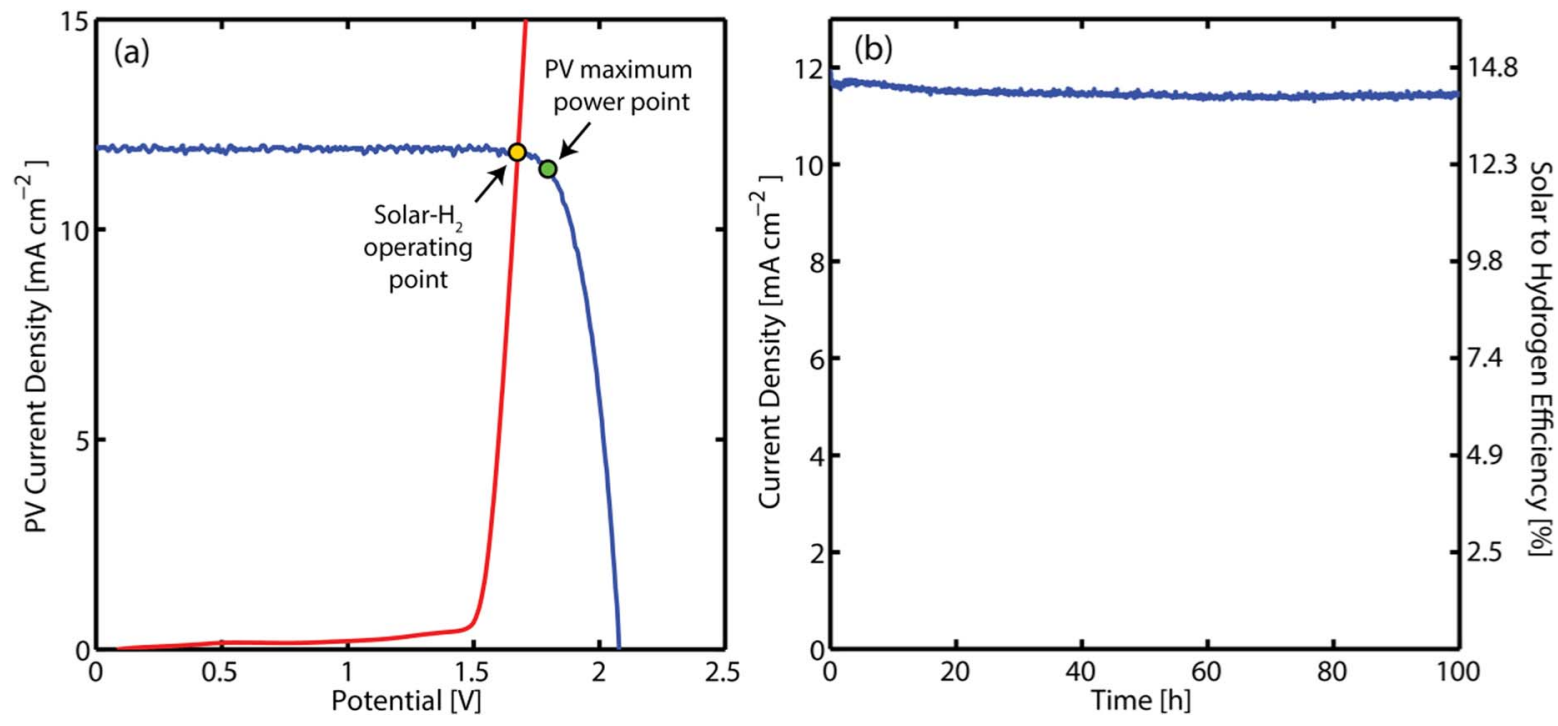

Figure 2. The current-voltage characteristics of SHJ module integrated with PEM electrolysis units shown in (a) demonstrate the optimized configuration of the photovoltaic and water-splitting components for high efficiency solar-hydrogen generation. The stability of its components allowed the device to operate stably at an average $14.2 \%$ SHE for prolonged periods, as demonstrated in (b). The illumination area used in the measurements presented in this figure was $5.7 \mathrm{~cm}^{2}$, while the MEA area used for electrolysis was $1.3 \mathrm{~cm}^{2}$.

\section{Results and Discussion}

In order to demonstrate the potential of SHJ cells in solar-hydrogen devices, a module consisting of three series-connected cells was fabricated following advanced and also scalable module manufacturing techniques. This module has suitable current-voltage characteristics (Fig. 2a) to drive the water splitting reaction at high current densties, as demonstrated by its high $\mathrm{V}_{\mathrm{OC}}(2.08 \mathrm{~V})$, short-circuit current density $\left(\mathrm{J}_{\mathrm{SC}}=11.9 \mathrm{~mA} / \mathrm{cm}^{2}\right)$, and solar-to-electricity conversion efficiency of $20.6 \%$ at its maximum power operating point $\left(\mathrm{J}_{\mathrm{mpp}}=11.6\right.$ $\mathrm{mA} / \mathrm{cm}^{2}, \mathrm{~V}_{\mathrm{mpp}}=1.78$ ). To trigger the generation of hydrogen, this module was integrated with a customized Nafion proton-exchange membrane (PEM) electrolysis unit. The flow plates used in the water splitting system were manufactured using a rapid-prototyping additive-manufacturing machine ${ }^{30}$ and the membrane electrode assembly implemented was based on Platinum (Pt) and Iridium Oxide $\left(\mathrm{IrO}_{\mathrm{x}}\right)$ electrocatalysts for the hydrogen and oxygen evolution reactions, respectively. PEM electrolysis units are widely used in commercial applications as they can operate at high current densities, only require pure water as the feed, produce nearly-pure hydrogen streams with faradaic efficiencies approaching $100 \%$, and can operate continuously for over 5 years. ${ }^{31}$ For efficient and cost-effective solar-hydrogen production, these solar water-splitting units should be operated at voltages slightly lower than the $\mathrm{V}_{\mathrm{mpp}}$ of the $\mathrm{PV}$ components used, which will avoid significant performance deterioration over the lifetime of the device. ${ }^{9,10,12}$ Fig. 2a shows that the SHJ module within the integrated solar-electrolysis device operates at a current density $\left(\mathrm{j}_{\mathrm{op}}\right)$ of $11.8 \mathrm{~mA} / \mathrm{cm}^{2}$ and a corresponding potential of $1.67 \mathrm{~V}$. This leads to an initial SHE of $14.5 \%$, which after thermal equilibration of the PV module stabilizes at $14.2 \%$. The Solar-to-Hydrogen Efficiency is calculated according to Eq. 1:

$$
S H E=\frac{j E^{0} \eta_{F}}{P_{\text {solar }}}
$$

where $j$ is the current density of the PV module, $E^{\circ}$ is the standard thermodynamic water splitting potential $(1.23 \mathrm{~V}), \eta_{F}$ is the faradaic efficiency and $P_{\text {solar }}$ is the power illuminating the SHJ modules (1000 $\mathrm{W} / \mathrm{m}^{2}$ ). Also, as the components used within this system are intrinsically stable, we have shown that the system can continuously produce $\mathrm{H}_{2}$ without performance degradation for over $100 \mathrm{~h}$ (Fig. 2b). Furthermore, as the overall hydrogen collection efficiency approaches $100 \%$ with minimum crossover across the membrane, these devices could be truly deployed for large scale solar-hydrogen production. Hydrogen and oxygen production rates over time are shown in Figure S6 in the Supplementary Information.

While the device described above represents a viable solution for solar-fuel generation in the short term, reaching scales of solarhydrogen production that satisfy the global energy needs would not be viable with the use of scarce noble-metals such as Platinum and Iridium. ${ }^{32}$ Alkaline water-splitting systems have historically dominated the electrochemical hydrogen production landscape, as they implement stable, inexpensive and earth-abundant Nickel (Ni) electrocatalysts. Since these systems operate at lower current density levels than their $\mathrm{Pt} / \mathrm{IrO}_{\mathrm{x}}$ counterparts, larger active electrocatalysis areas are required for their integration into solar-hydrogen generators. To achieve the current levels required by SHJ modules at potentials lower than $\mathrm{V}_{\mathrm{mpp}}$, a set of two high-surface area microstructured Ni electrodes was used in an electrolysis cell operated under a $1 \mathrm{M}$ potassium hydroxide electrolyte. Based on the photoelectrochemical characteristics of the integrated PV and electrocatalyst components (Fig. 3a), this device operated at an average SHE of $14.2 \%$. As the Ni electrocatalysts are intrinsically stable under basic electrolytes, this high-efficiency level of solar to hydrogen conversion was sustained for more than 100 h (Fig. 3b). This high efficiency demonstration suggests that Si-based solar-hydrogen generators with earth-abundant electrocatalysts can have the potential to trigger deployment of reliable solar-hydrogen systems at large scale.

\section{Technological Outlook and Conclusions}

The SHJ module developed and implemented in this study led to a $44 \%$ efficiency increase from the previous highest performing Si-based solar-hydrogen system. ${ }^{19}$ By series-connecting three SHJ solar cells with an advanced interconnection method, we fabricated a module that operated at an appropriate voltage to directly power the electrolysis unit without using any further electronics between both components. This approach led to the demonstration of an intrinsically stable, silicon-based solar-driven water splitting system with the unprecedented SHE of $14.2 \%$ for a duration of at least $100 \mathrm{~h}$. Furthermore, the solar-fuel conversion efficiencies achieved in this study surpass those of recently demonstrated perovskite based systems. ${ }^{14}$ Alternative systems involving physically integrated photo-electrochemical (PEC) cells have attracted the attention of the scientific community, even when their practical implementation faces significant challenges. 

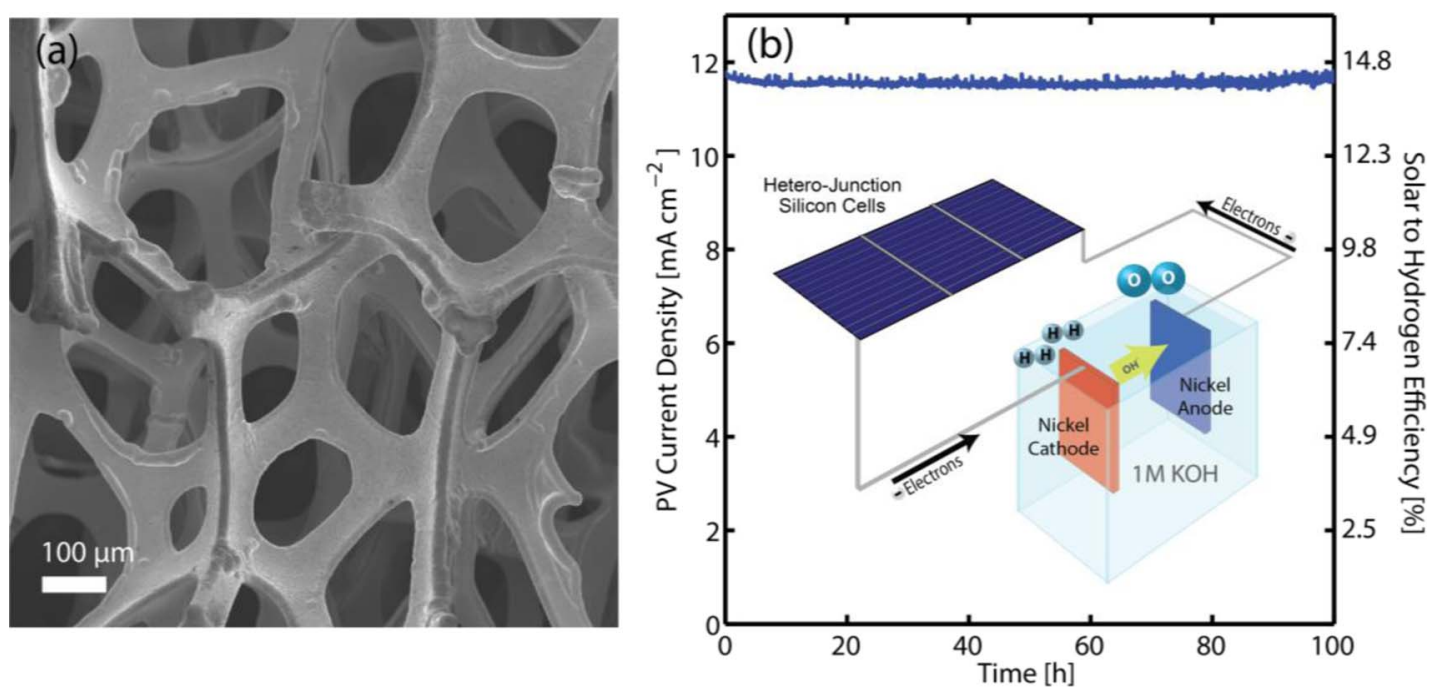

Figure 3. Earth-abundant Nickel electrocatalysts were implemented in SHJ-based solar-hydrogen generators. The microporous structure of the nickel electrodes, as shown in the scanning-electron micrograph in (a), provided the high active surface-area required to sustain the current output of the PV module. The long term performance demonstrated in (b) shows that high SHE can be sustained for over 100 hours of operation. During these measurements, the illumination area was kept at $5.7 \mathrm{~cm}^{2}$, while the projected area of the microporous electrodes used was $60 \mathrm{~cm}^{2}$.

PEC components have poor stability under strong electrolytes, constrain the positioning of the electrocatalysts to the surface of lightabsorber materials, face parasitic irradiation losses in the catalysts, electrolyte, protection layers, and generated bubbles, and inherently require longer pathlenghts for ion migration. On the other side of the spectrum, approaches that implement grid-distributed PV components and electrolysis units will suffer from efficiency losses in power inverters, as well as directly affect the operation of the electrical grid. Stand-alone electrically-coupled PV-electrolysis approaches, such as the one proposed in this work, circumvent these issues and have the potential to significantly disrupt the clean energy storage landscape.

Additional efficiency improvements can be achieved by using interdigitated back contacted SHJ cells ${ }^{23,33}$ or fine-line electroplated metallization $;^{34}$ improving the infrared light management ${ }^{35}$ the transparency of the front side of the device $e^{36-39}$ and implementing thinner a-Si:H passivation and doped layers on the front side of the device. SHJ cells fabricated in the same configuration as the ones used in this study (i.e. with contacts on both sides of the device) have reached certified current densities up to $39.5 \mathrm{~mA} / \mathrm{cm}^{2},{ }^{22}$ which could lead to Solar- $\mathrm{H}_{2}$ generators with SHE approaching $16 \%$.

Furthermore, the highest certified efficiencies and current densities $\left(\right.$ Eff $=25.6 \% ; \mathrm{J}_{\mathrm{SC}}=41.8 \mathrm{~mA} / \mathrm{cm}^{2} ; \mathrm{V}_{\mathrm{OC}}=740 \mathrm{mV} ; \mathrm{FF}=$ $82.7 \%$ ) for SHJ cells have so far been obtained in a back contacted configuration. ${ }^{23,33}$ In such cells, both electrical contacts are placed on the back of the device. As there is no metallization on the front side of the cells, shadowing losses are avoided, leading to enhanced current densities. Within this configuration, and considering similar interconnection losses to the ones presented in our study, modules based on these cells could lead to SHEs as high as $16.6 \%$. This proposed pathway of efficiency improvements in SHJ-based solar water-splitting devices could disruptively change the prospect for the implementation of solar-fuel technologies. Furthermore, the growth, scalability, availability and stability of silicon heterojunction photovoltaics in combination with earth-abundant catalysts can lead to large-scale solar-to-hydrogen conversion systems that operate at high efficiencies and produce clean fuels at affordable price levels.

\section{Acknowledgments}

The authors acknowledge the support from the Swiss National Science Foundation: Nano-Tera project 20NA21_145936 "Solar integrated Nano Electrolyzer: SHINE". The authors also thank Roland
Dupuis (EPFL) for his help with the additive manufacturing process and Jonathan Champliaud (CSEM) for his help with the module fabrication.

\section{References}

1. D. Gust, T. A. Moore, and A. L. Moore, Acc. Chem. Res., 42, 1890 (2009).

2. International Energy Agency (IEA), Key World Energy Statistics 2015.

3. J. A. Turner, Science, 305, 972 (2004)

4. S. Chu and A. Majumdar, Nature, 488, 294 (2012).

5. N. S. Lewis and D. G. Nocera, Proc. Natl. Acad. Sci. U. S. A., 103, 15729 (2006).

6. J. W. Ager, M. Shaner, K. Walczak, I. D. Sharp, and S. Ardo, Energy Environ. Sci., 8, 2811 (2015).

7. M. A. Modestino, S. M. H. Hashemi, and S. Haussener, Energy Environ. Sci., 9, 1533 (2016).

8. M. A. Modestino and S. Haussener, Annu. Rev. Chem. Biomol. Eng., 6, 13 (2015).

9. R. Sathre, C. D. Scown, W. R. Morrow, J. C. Stevens, I. D. Sharp, J. W. Ager, K. Walczak, F. A. Houle, and J. B. Greenblatt, Energy Environ. Sci., 7, 3264 (2014).

10. M. Dumortier, S. Tembhurne, and S. Haussener, Energy Environ. Sci., 8, 3614 (2015).

11. A. Nakamura, Y. Ota, K. Koike, Y. Hidaka, K. Nishioka, M. Sugiyama, and K. Fujii, Appl. Phys. Express, 8, 107101 (2015).

12. C. A. Rodriguez, M. A. Modestino, D. Psaltis, and C. Moser, Energy Environ. Sci., 7, 3828 (2014).

13. T. J. Jacobsson, V. Fjällström, M. Sahlberg, M. Edoff, and T. Edvinsson, Energy Environ. Sci., 6, 3676 (2013).

14. J. Luo, D. A. Vermaas, D. Bi, A. Hagfeldt, W. A. Smith, and M. Grätzel, Adv. Energy Mater, 6, 13 (2016).

15. T. C. Sum and N. Mathews, Energy Environ. Sci., 7, 2518 (2014).

16. R. M. Swanson, Science, 324, 891 (2009).

17. European Commission Joint Research Center, Institute for Energy, PV Status report 2014.

18. International Technology Roadmap for Photovoltaic (ITRPV), 2015 Results, Seventh Editon (March 2016).

19. C. R. Cox, J. Z. Lee, D. G. Nocera, and T. Buonassisi, Proc. Natl. Acad. Sci. U. S. A., 111, 14057 (2014).

20. M. Tanaka, M. Taguchi, T. Matsuyama, T. Sawada, S. Tsuda, S. Nakano, H. Hanafusa, and Y. Kuwano, Jpn. J. Appl. Phys., 31, 3518 (1992).

21. C. Battaglia, A. Cuevas, and S. De Wolf, Energy Environ. Sci., 9, 1552 (2016).

22. M. Taguchi, A. Yano, S. Tohoda, K. Matsuyama, Y. Nakamura, T. Nishiwaki, K. Fujita, and E. Maruyama, IEEE J. Photovolt., 4, 96 (2014).

23. K. Masuko, M. Shigematsu, T. Hashiguchi, D. Fujishima, M. Kai, N. Yoshimura, T. Yamaguchi, Y. Ichihashi, T. Mishima, N. Matsubara, T. Yamanishi, T. Takahama, M. Taguchi, E. Maruyama, and S. Okamoto, IEEE J. Photovolt., 4, 1433 (2014).

24. E. Kobayashi, N. Nakamura, K. Hashimoto, and Y. Watabe, Proc. of 28th EU PVSEC, Paris, France (2013), pp. 691.

25. G. Cattaneo, A. Faes, H.-Y. Li, F. Galliano, M. Gragert, Y. Yao, R. Grischke, T. Söderström, M. Despeisse, C. Ballif, and L.-E. Perret-Aebi, Photovoltaics International, 27, 82 (2015).

26. J. Escarré, K. Söderström, M. Despeisse, S. Nicolay, C. Battaglia, G. Bugnon, L. Ding, F. Meillaud, F.-J. Haug, and C. Ballif, Sol. Energy Mater. Sol. Cells, 98, 185 (2012). 
27. J.-W. Schüttauf, G. Bugnon, M. Stuckelberger, S. Hänni, M. Boccard, M. Despeisse, F.-J. Haug, F. Meillaud, and C. Ballif, IEEE J. Photovolt, 4, 757 (2014).

28. A. Lo, M. Despeisse, R. Théron, and C. Ballif, Proc. of 25th EU PVSEC, Valencia, Spain (2010), pp. 4232

29. G. Chisholm, P. J. Kitson, N. D. Kirkaldy, L. G. Bloor, and L. Cronin, Energy \& Environmental Science, 7, 3026 (2014).

30. G. Chisholm, P. J. Kitson, N. D. Kirkaldy, L. G. Bloor, and L. Cronin, Energy Environ. Sci., 7, 3026 (2014)

31. M. Carmo, D. L. Fritz, J. Mergel, and D. Stolten, Int. J. Hydrogen Energy, 38, 4901 (2013).

32. E. Kemppainen, A. Bodin, B. Sebok, T. Pedersen, B. Seger, B. Mei, D. Bae, P. C. K. Vesborg, J. Halme, O. Hansen, P. D. Lund, and I. Chorkendorff, Energy Environ. Sci., 8, 2991 (2015).

33. A. Tomasi, B. Paviet-Salomon, D. Lachenal, S. Martin de Nicolas, A. Descoeudres, J. Geissbuhler, S. De Wolf, and C. Ballif, IEEE J. Photovolt., 4, 1046 (2014).
34. J. Geissbühler, S. De Wolf, A. Faes, N. Badel, Q. Jeangros, A. Tomasi, L. Barraud, A. Descoeudres, M. Despeisse, and C. Ballif, IEEE J. Photovolt, 4, 1055 (2014).

35. Z. C. Holman, A. Descoeudres, S. De Wolf, and C. Ballif, IEEE J. Photovolt., 3, 1243 (2013).

36. L. Barraud, Z. C. Holman, N. Badel, P. Reiss, A. Descoeudres, C. Battaglia, S. De Wolf, and C. Ballif, Sol. Energy Mater. Sol. Cells, 115, 151 (2013).

37. C. Battaglia, S. Martin de Nicolas, S. De Wolf, X. Yin, M. Zheng, C. Ballif, and A. Javey, Appl. Phys. Lett., 104, 113902 (2014).

38. J. Geissbühler, J. Werner, S. Martin de Nicolas, L. Barraud, A. Hessler-Wyser, M. Despeisse, S. Nicolay, A. Tomasi, B. Niesen, S. De Wolf, and C. Ballif, Appl. Phys. Lett., 107, 081601 (2015).

39. J. Bullock, M. Hettick, J. Geissbühler, A. J. Ong, T. Allen, C. M. Sutter-Fella, T. Chen, H. Ota, E. W. Schaler, S. De Wolf, C. Ballif, A. Cuevas, and A. Javey, Nature Energy, 1, 15031 (2016) 